Research Paper

\title{
Metformin in combination with JS-K inhibits growth of renal cell carcinoma cells via reactive oxygen species activation and inducing DNA breaks
}

\author{
Yuwan Zhao*, Qiuming Luo ${ }^{*}$, Jierong Mo*, Jianwei Li, Dongcai Ye, Zhixian Ao, Lixin Chen, Jianjun Liu ${ }^{\bowtie}$ \\ Laboratory of Urology, Affiliated Hospital of Guangdong Medical University, Zhanjiang, Guangdong 524001, China \\ *Contributed equally \\ $\square$ Corresponding author: Dr Jianjun Liu, Laboratory of Urology, Affiliated Hospital of Guangdong Medical University, 57 Renmin Street South, Zhanjiang, \\ Guangdong 524001, China. Email: jianjunliulab@163.com \\ (c) The author(s). This is an open access article distributed under the terms of the Creative Commons Attribution License (https://creativecommons.org/licenses/by/4.0/). \\ See http://ivyspring.com/terms for full terms and conditions.
}

Received: 2019.05.05; Accepted: 2020.02.06; Published: 2020.03.31

\begin{abstract}
Metformin (MET) is taken as a principal medication for remedying Type 2 diabetes mellitus. Its anti-tumor effect has been reported increasingly, but the precise mechanism of it remains unclear. This study aims to explore the efficacy of MET and MET combined with nitric oxide donor prodrug JS-K on the proliferation, apoptosis, and DNA damage in human renal cell carcinoma (RCC) cells, and investigate the possible molecular mechanism involved. The cell proliferation was tested through methyl-tetrazolium assay and cell apoptosis was ascertained by flow cytometry. The dihydroethidium and JC-1 fluorescent methods were used to detect Reactive oxygen species (ROS) and mitochondrial transmembrane potential $(\Delta \Psi \mathrm{m})$, respectively. Proteins associated with apoptosis and DNA damage were evaluated by Western blotting. Results showed that MET and JS-K could suppress cell growth, and the inhibition concentration 50 of treatment with MET combined with JS-K (MET + JS-K) showed more toxicity than individual agents on RCC cells. This augmented toxicity was associated with intracellular reactive oxygen species (ROS) level, mitochondrial membrane potential alteration, and induced DNA breaks. The results of Western blotting showed that the expression level of pro-apoptotic proteins, such as Bax, Bak, caspase-3, and caspase-9, was up-regulated, and the anti-apoptotic protein $\mathrm{Bcl}-2$ was down-regulated after treatment using MET alone and MET + JS-K, correspondingly. Moreover, MET + JS-K inhibited the expression of cellular PCNA and $\mathrm{Rad} 51$, and immunofluorescence analysis of $\mathrm{YH} 2 \mathrm{AX}$ proved that MET + JS-K enhanced DNA damage. In summary, the results of this research indicated that MET and JS-K inhibited RCC cell growth by activating ROS, targeting mitochondria-dependent apoptotic pathways, and inducing DNA breaks.
\end{abstract}

Key words: metformin, JS-K, renal cell carcinoma, ROS, DNA breaks

\section{Introduction}

Renal cell carcinoma (RCC) is a frequent progressive cancer of urologic system with poor prognosis and accounts for $3 \%$ of adult malignancies $[1,2]$. Currently, the approved therapy for patients with early partial RCC is radical nephrectomy [3]. However, approximately $25 \%-30 \%$ of people who suffer from RCC have obvious metastatic or progressive disease, and the 5-year survival rate is very low (only 10\%-12\%) [2]. Radiotherapy and chemotherapy are treatment options that can be selected by patients with advanced RCC who missed opportunities for surgical treatment [4]. However, according to the clinical experience, RCC is extremely insensitive to radiotherapy and conventional chemotherapy drugs $[5,6]$. Therefore, new drugs with anti-renal cancer effect must be discovered.

MET is a first-line drug for treating Type 2 diabetes. MET increases the absorption and utilization of glucose by skeletal muscles, reduces the insulin resistance of peripheral tissues, and inhibits gluconeogenesis (the production of glucose) in the liver, thereby reducing the blood glucose level [7-10]. 
In 2005, a retrospective analysis by Evans [11] found that the tumor incidence decreased in Type 2 diabetes patients who took MET, thereby indicating the potential anti-tumor effects of MET. In recent years, MET has attracted increasing attention given its evident anti-tumor effect. It mainly inhibits the growth, invasion, and metastasis of virulent tumors like breast cancer, lung cancer, esophageal cancer, nasopharyngeal cancer, and melanoma, via suppressing cell proliferation, prompting cell apoptosis, and blocking cell cycle [12-17].

Nitric oxide (NO) is a lipophilic signaling molecule that is easy to diffuse and has a short biological half-life. NO donor drugs, such as JS-K (C13H16N6O8, CAS-No., 205432-12-8), which was developed by the US National Cancer Institute (NCI), has been reported to be extremely cytotoxic to many kinds of human cancer cells but has no obvious toxicity to normal human cells [18-22].

The emergence of $\gamma \mathrm{H} 2 \mathrm{AX}$ is one of the earliest cellular responses to DNA double strand breakage, therefore, $\gamma \mathrm{H} 2 \mathrm{AX}$ expression was positively correlated with the degree of DNA damage. PCNA is closed connected with DNA replication and replication-associated processes, while Rad51 plays a critical role in DNA replication and homologous recombination repair, to some extent, the expression of PCNA and Rad51 can reflect the repair level of DNA [23-25].

In this research, we explored the effects of MET and MET combined with JS-K (MET + JS-K) in vitro on proliferation, apoptosis, and DNA damage of RCC cell lines (A498 and ACHN). Our findings demonstrate that MET and JS-K inhibit RCC cell growth by activating reactive oxygen species (ROS) and inducing DNA breaks.

\section{Materials and Methods}

\section{Cell culture}

Human RCC cells (A498 and ACHN) and the normal renal cell line (HK-2) were obtained from Guangzhou Jennio Biological Technology Co., Ltd. (Guangzhou, China). A498 cells were grown in RPMI 1640 medium (GIBCO, Thermo Fisher Scientific, Inc., Waltham, MA, USA). ACHN and HK-2 cells were cultured in Dulbecco's modified Eagle medium (DMEM) (GIBCO, Thermo Fisher Scientific, Inc., Waltham, MA, USA). All culture media were supplemented with $10 \%(\mathrm{v} / \mathrm{v})$ fetal bovine serum (FBS; GIBCO, Thermo Fisher Scientific, Inc., Waltham, MA, USA) at $37^{\circ} \mathrm{C}$ in a humidified atmosphere that contained 5\% $\mathrm{CO}_{2}$. The conventional digestion was performed when cell confluence reached $80 \%-90 \%$, and the media were refreshed every 2 or 3 days.

\section{Reagents and antibodies}

MET was purchased from Beijing Solarbio Science \& Technology Co., Ltd. (Beijing, China) and dissolved in phosphate-buffered saline (PBS) as a stock solution of $2 \mathrm{M}$. The NO prodrug JS-K was purchased from Santa Cruz Biotechnology, Inc. (Dallas, TX, USA) and dissolved in dimethyl sulfoxide (DMSO) as a stock solution of $5 \mathrm{mM}$. N-acetylcysteine (NAC) and glutathione disulfide (GSSG) were obtained from Beyotime Institute of Biotechnology (Shanghai, China) and dissolved in PBS to concentrations of $100 \mathrm{mM}$ and $5 \mathrm{mM}$ respectively. All stock solutions were stored at $-20^{\circ} \mathrm{C}$ for further use. Antibodies against Bak, Bcl-2-associated X protein, B-cell lymphoma 2, caspase-3, caspase-9, cytochrome c (Cyto-C), Phosphorylated histone H2AX ( $\gamma \mathrm{H} 2 \mathrm{AX})$, DNA repair protein Rad51, and Proliferating cell nuclear antigen (PCNA) were obtained from Cell Signaling Technology, Inc. (Danvers, MA, USA), and antibody against GAPDH was purchased from Abcam (Cambridge, UK). Horseradish peroxidaseconjugated IgG secondary antibodies were purchased from EarthOx Life Sciences (Millbrae, CA, USA).

\section{Cell viability assay}

Cell viability was assessed by methyltetrazolium (MTT) assay. On the first day, the cells of ACHN, A498, and HK-2 were seeded into a 96-well plate at $5 \times 10^{3}$ cells/well. On the second day, various concentrations of MET and JS-K were added to the wells. Then, the cells of each well were added $20 \mu \mathrm{L}$ of MTT (3-(4, 5-dimethylthiazol-2-yl)-2, 5-diphenyl tetrazolium bromide) (Sigma Aldrich, St. Louis, MO, USA) and incubated at $37^{\circ} \mathrm{C}$ for $4 \mathrm{~h}$. Subsequently, the medium of each well was replaced by DMSO $(150 \mu \mathrm{L})$ to dissolve the sediment and were shaken for $10 \mathrm{~min}$ in the dark. The absorbance of the solution was detected at $492 \mathrm{~nm}$ using a Multiskan Ascent microplate photometer (EnSpire 2300 Multilabel Reader, PE, USA).

\section{Cytotoxicity assay}

The lactate dehydrogenase (LDH) Cytotoxicity Assay Kit (Beyotime) was used to measure the cytotoxicity of MET, JS-K, and their combination. Briefly, the cells were treated with series concentrations of MET and JS-K for $24 \mathrm{~h}$ after they were seeded in 96-well plates at $5 \times 10^{3}$ cells/well overnight, the culture media were centrifuged at $400 \times$ $\mathrm{g}$ for $5 \mathrm{~min}$. The supernatants $(120 \mu \mathrm{L} /$ well $)$ were transferred into new $96-$-well plates, and $60 \mu \mathrm{L}$ of $\mathrm{LDH}$ detection reagent was added to each well. The plates were incubated at room temperature in the dark for 30 min, and the absorbance of the formazan was detected at $490 \mathrm{~nm}$ using a reader (EnSpire 2300 Multilabel 
Reader, PE, USA).

\section{Colony formation assay}

ACHN and A498 cells were plated into 6-well plates and treated with various concentrations MET and JS-K for $24 \mathrm{~h}$. The cells were washed with PBS and trypsinized (using $0.25 \%$ trypsin). Then, 2,000 viable cells were plated into new 6-well plates. ACHN cells were cultured at $37^{\circ} \mathrm{C}$ for an additional 14 days while A498 were cultured for an additional 10 days. The cells were fixed using $4 \%$ paraformaldehyde, and then stained with crystal violet (Beyotime Institute of Biotechnology, Shanghai, China). The macroscopic colonies ( $>50$ cells) were photographed using a digital camera, and the number of colonies formed was counted.

\section{Apoptosis assay}

The fluorescein isothiocyanate (FITC)-labeled Annexin V Apoptosis Detection kit (BD Biosciences, Franklin Lakes, NJ, USA) was used to quantify apoptotic cells. ACHN and A498 cells were collected after treatment with various concentrations of MET and JS-K for $24 \mathrm{~h}$, then washed with PBS, and resuspended in binding buffer. Subsequently, cells were stained with FITC-labeled annexin V and propidium iodide for $15 \mathrm{~min}$ at room temperature in dark. The flow cytometry BD FACSDiva 6.1 software was used to analyze the stained cells within $1 \mathrm{~h}$. The excitation wavelength of the fluorophore was $488 \mathrm{~nm}$, the emission wavelength of the fluorophore was PI: 564-606nm, FITC: 515-545nm.

\section{Intracellular ROS detection}

The ROS Assay Kit (Beyotime, Beijing, China) was used to detect ROS production in ACHN and A498 cells. After being treated with various concentrations of MET and JS-K for $24 \mathrm{~h}$, the ACHN and A498 cells were collected and resuspended with a serum-free medium that contained DCFH-DA (10 $\mu \mathrm{M})$. After incubation for $20 \mathrm{~min}$ at $37^{\circ} \mathrm{C}$ in dark, cells were analyzed by flow cytometry with excitation at $488 \mathrm{~nm}$ and emission at $525 \mathrm{~nm}$. The results were analyzed using BD FACSDiva 6.1 software.

\section{Measurement of mitochondrial membrane potential $(\Delta \Psi \mathrm{m})$}

JC-1 Mitochondrial Membrane Potential Assay Kit (Beyotime, Shanghai, China) was used to measure mitochondrial membrane potential in $\mathrm{ACHN}$ and A498 cells. Briefly, ACHN and A498 cells were plated into 6-well plates at $3 \times 10^{5}$ cells/well and cultivated overnight. Subsequently, MET and JS-K of series concentrations were taken to treat these cells for $24 \mathrm{~h}$. The cells were harvested, washed twice with PBS, and then resuspended in $0.5 \mathrm{~mL}$ of complete medium containing $10 \mu \mathrm{g} / \mathrm{mL} \mathrm{JC}-1$ at $37^{\circ} \mathrm{C}$ for $20 \mathrm{~min}$. Finally, using the BD FACSDiva 6.1 software to analyze the cells after collected.

\section{Western blot analysis}

The A498 and ACHN cells treated with series of concentrations of MET and JS-K for $24 \mathrm{~h}$ were lysed in radioimmunoprecipitation assay (RIPA) buffer (Beyotime, Shanghai, China) supplemented with $1 \mathrm{mM}$ phenylmethanesulfonyl fluoride (PMSF) (Beyotime, Shanghai, China) to extract the whole cell protein at $4^{\circ} \mathrm{C}$. However, Cyto-C in the cytoplasm was extracted using Cell Mitochondria Isolation Kit (Beyotime, Shanghai, China). About $30 \mu \mathrm{g}$ of protein were separated on a $10 \%$ sodium dodecyl sulfatepolyacrylamide gel and then blotted onto polyvinylidene fluoride (PVDF) membranes (Millipore, Bedford, MA, USA) at $4^{\circ} \mathrm{C}$. Subsequently, $5 \%$ non-fat milk in tris-buffered saline and 1\% Tween 20 (TBST) were used to block the PVDF membranes at room temperature for $1 \mathrm{~h}$ and treated with specific primary antibodies with the following dilutions: Bak, 1:1,000; caspase-3, 1:1,000; caspase-9, 1:1,000; Bcl-2, 1:1,000; Bax, 1:1,000; Cyto-C, 1:1,000; PCNA, 1:1,000; Rad51, 1:1,000; $\gamma \mathrm{H} 2 \mathrm{AX}, 1: 1,000 ;$ and GAPDH, 1:100,000 overnight at $4^{\circ} \mathrm{C}$. Blots were washed thrice with TBST and the HRP-conjugated IgG-secondary antibody (dilution, 1:10,000) was added and the membranes were incubated at room temperature for $2 \mathrm{~h}$. The protein bands were detected using an enhanced chemiluminescence kit (EMD Millipore, Billerica, MA, USA) with Tanon 5200 chemiluminescent imaging system (Shanghai, China).

\section{Immunofluorescence analysis}

After treating ACHN and A498 cells grown on chamber slides with various concentrations of MET and JS-K for $48 \mathrm{~h}$, the cells were washed with PBS, and fixed with $4 \%$ paraformaldehyde at room temperature for $30 \mathrm{~min}$. The cells were permeabilized in $0.2 \%$ Triton X-100 for 30 min after being washed thrice with PBS, and then blocked for $1 \mathrm{~h}$ in PBS containing $1 \%$ BSA (Solarbio, Beijing, China). $100 \mu \mathrm{L}$ of $1 \%$ BSA containing 1:100 diluted anti- $\gamma \mathrm{H} 2 \mathrm{AX}$ polyclonal $\mathrm{Ab}$ (CST) was used to suspend the cells overnight at $4{ }^{\circ} \mathrm{C}$. Next day, the cells were incubated in $100 \mu \mathrm{L}$ of 1:100 diluted Alexa Fluor 488-conjugated anti-rabbit IgG (Thermo Fischer Scientific, Carlsbad, CA, USA) for $2 \mathrm{~h}$ at room temperature keep away from light after being washed twice with PBS. After washing the cells thrice with PBS, the Hoechst 33342 (Sigma-Aldrich, St. Louis, MO, USA) was used to stain the cells for $3 \mathrm{~min}$, and the cells were photographed using a microscope (Olympus FV3000, Tokyo, Japan). 


\section{Statistical analysis}

All the data analysis was performed using SPSS 19.0 software (SPSS, Inc., Chicago, IL, USA). One-way ANOVA test followed by a post-hoc test-LSD was used to determine the significance. ${ }^{*} p<0.05,{ }^{* *} p<0.01$, and $* * * p<0.001$ were considered statistically significant. All experiments were performed in triplicate. Data were expressed as the means \pm standard deviation.

\section{Results}

\section{MET inhibits RCC cell growth}

The proliferation of cells was detected by MTT assay. MET $(1,5,10,20$, and $40 \mathrm{mM})$ were used to treat the RCC cell lines - ACHN and A498, and HK-2 (a normal renal cell line) for 24,48 , and $72 \mathrm{~h}$. Data showed that MET inhibited proliferation of ACHN and A498 cell in a concentration- and time-dependent manner (Figure 1A), whereas MET did not significantly affect the viability of HK-2 cells up to 20
$\mathrm{mM}$ concentrations (Figure 1B). The cytotoxicity of MET was investigated by LDH Cytotoxicity Assay Kit, and the data showed that treatment with MET for $24 \mathrm{~h}$ increased cytotoxicity (Figure 1C) in RCC cells in a concentration-dependent manner. Morphologic changes in renal carcinoma cells were observed through phase contrast microscopy. After treatment with $\operatorname{MET}(0,5,10$, and $20 \mathrm{mM})$ for 24 and $48 \mathrm{~h}$, the degree of confluence in A498 and ACHN were significantly decreased in conjunction with marked morphologic changes, that is, cells appeared as atypical shape, shrunken and rounded, and detached from the culture dish (Figure 1D). A colony formation assay was used to test the effect of MET on tumor cell colony formation. Compared to the control group, the colony counts of RCC cells treated with $\operatorname{MET}(0,5,10$, and $20 \mathrm{mM}$ ) for $24 \mathrm{~h}$ were significantly decreased (Figure 1E and F). Collectively, these data suggested that MET evidently inhibited the cell growth of the RCC cell lines ACHN and A498 but only minimally affected the nonmalignant HK-2 cells.
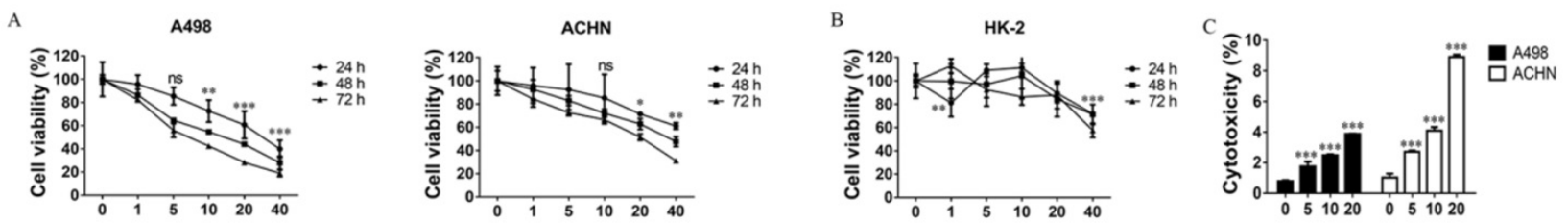

D

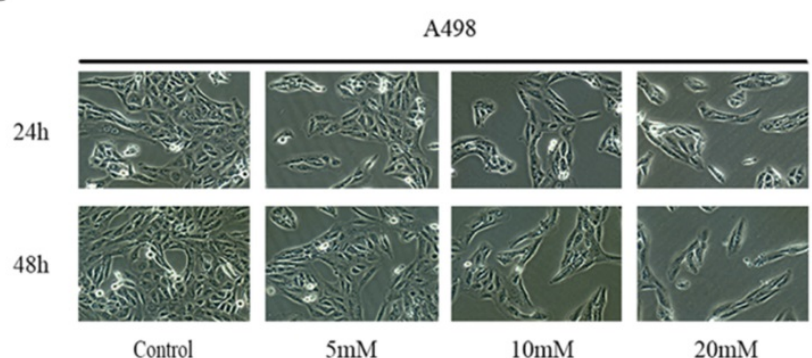

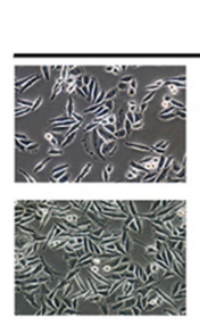

Control

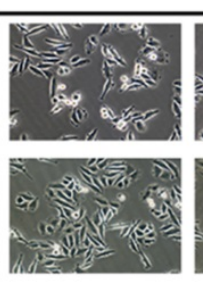

$5 \mathrm{mM}$
ACHN

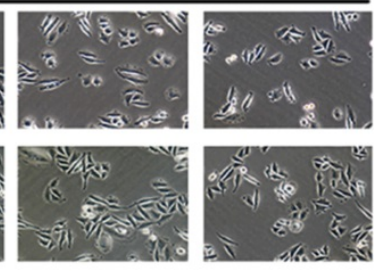

$10 \mathrm{mM}$

$20 \mathrm{mM}$

E

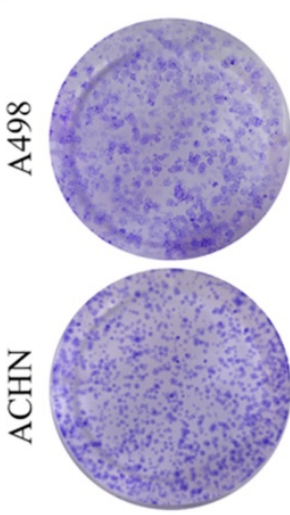

Control

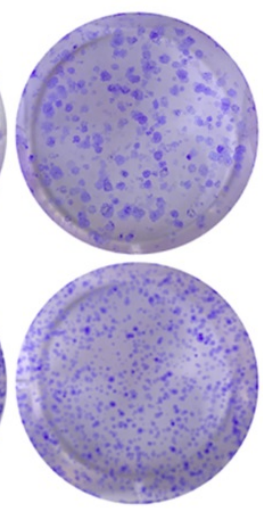

$5 \mathrm{mM}$

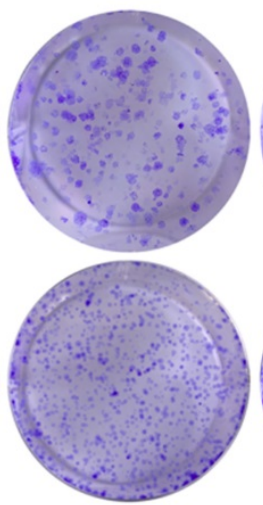

$10 \mathrm{mM}$

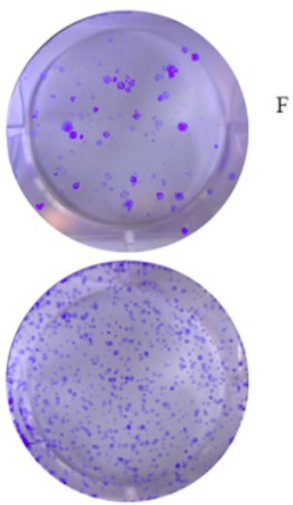

$20 \mathrm{mM}$

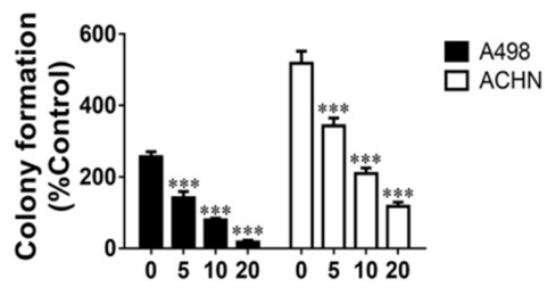

Figure 1. Effects of MET on RCC cell growth. Cells were treated with 1, 5, 10, 20, and $40 \mathrm{mMMET}$ for 24,48 , and $72 \mathrm{~h}$. The MTT assay was performed to determine cell viability. (A) MET inhibited the proliferation of RCC cell lines ACHN and A498 in a concentration- and time-dependent manner. (B) MET did not inhibit cell proliferation in normal renal cell HK-2. (C) Cytotoxicity of MET was investigated by LDH Cytotoxicity Assay Kit. (D) RCC cell lines ACHN and A498 were treated with various concentrations of MET (5, 10 , and $20 \mathrm{mM}$ ) for 24 and $48 \mathrm{~h}$. Morphologic changes (magnification, x100) in RCC cells were examined by phase contrast microscopy. (E and F) Cells were treated with MET $(5,10$, and $20 \mathrm{mM})$ for $24 \mathrm{~h}$. Colony formations were stained and counted. The data are presented as the mean \pm SD for three experiments. $* P<0.05$, $* * P<0.01$, and $* * * P<0.001$ compared with untreated cells. 


\section{MET promotes RCC cell apoptosis by} increasing ROS production and activating the mitochondria-dependent apoptotic pathway

The apoptosis-inducing effect of MET on RCC cells was evaluated by flow cytometry. The RCC cells were treated with MET $(5,10$, and $20 \mathrm{mM})$ for $24 \mathrm{~h}$ to assess whether it induces apoptosis in a concentration-dependent manner (Figure 2A and B). The dihydroethidium and JC-1 fluorescent methods were used to measure the effect of MET on ROS production and mitochondrial transmembrane potential $(\Delta \psi \mathrm{m})$. The RCC cells treated with a series of concentrations of MET for $24 \mathrm{~h}$ were examined for total ROS levels and mitochondrial transmembrane potential. A significant increase in the total ROS (Figure 2D) and a decrease in the mitochondrial transmembrane potential (Figure 2E) were observed in the RCC cells ACHN and A498 in a concentrationdependent manner. These data suggested that MET induces ROS production and promotes mitochondrial dysfunction and mitochondria-dependent apoptosis.

A
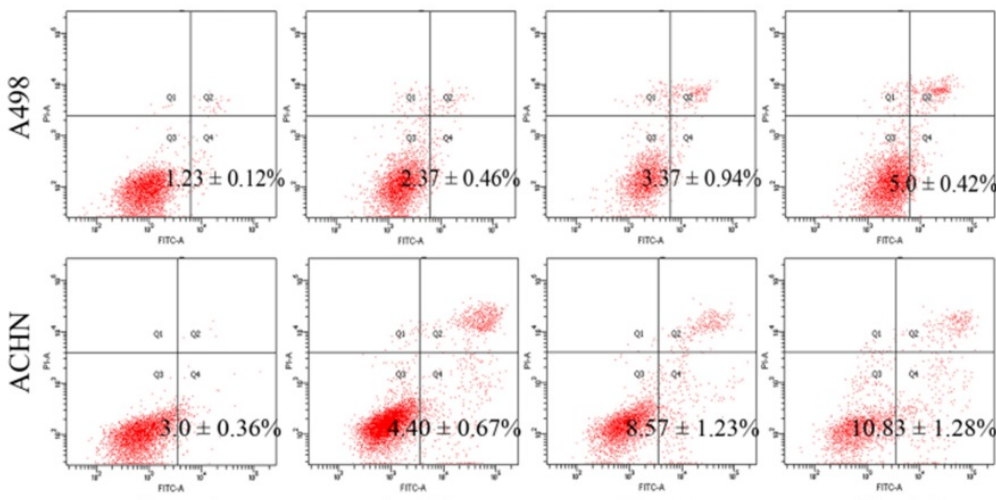

B
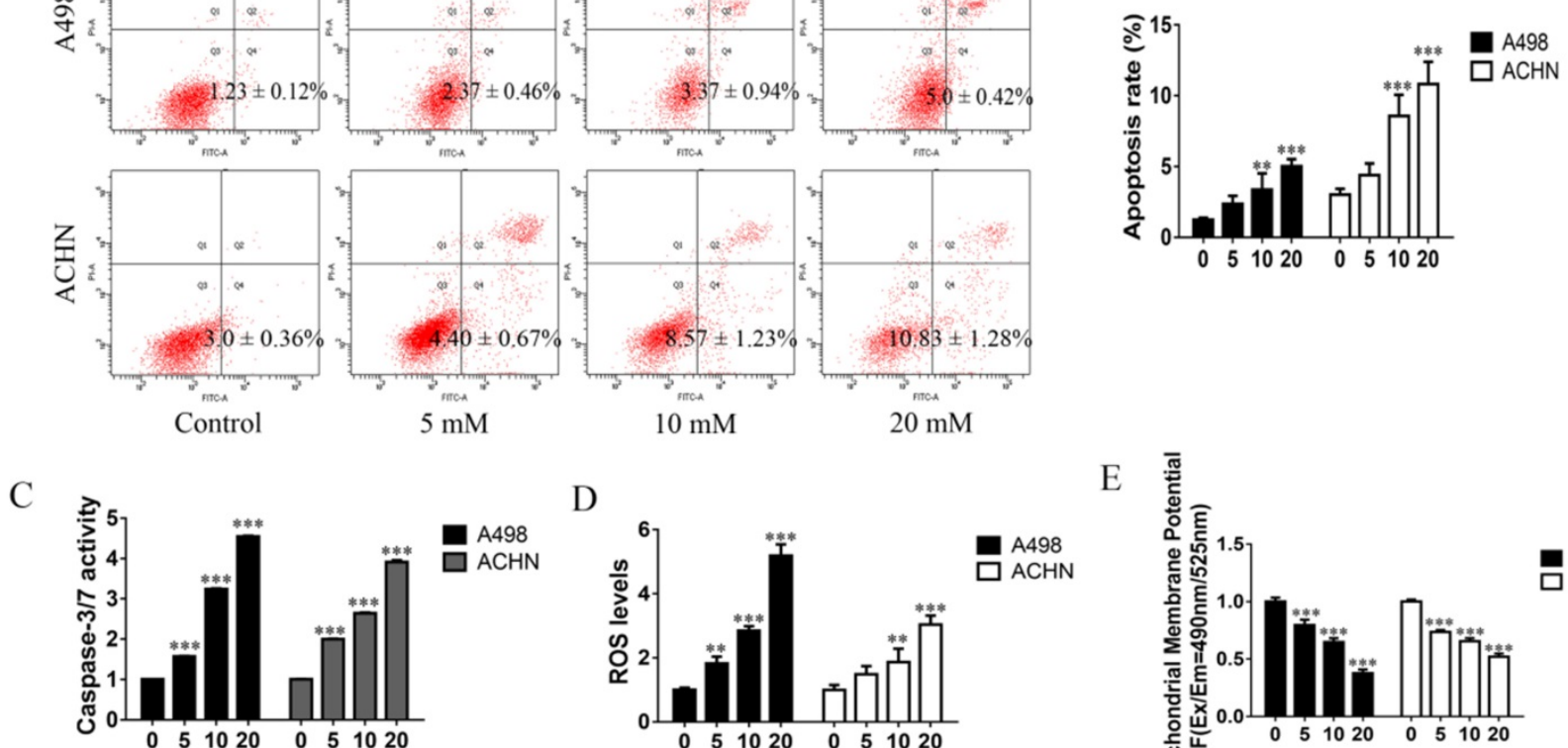

D
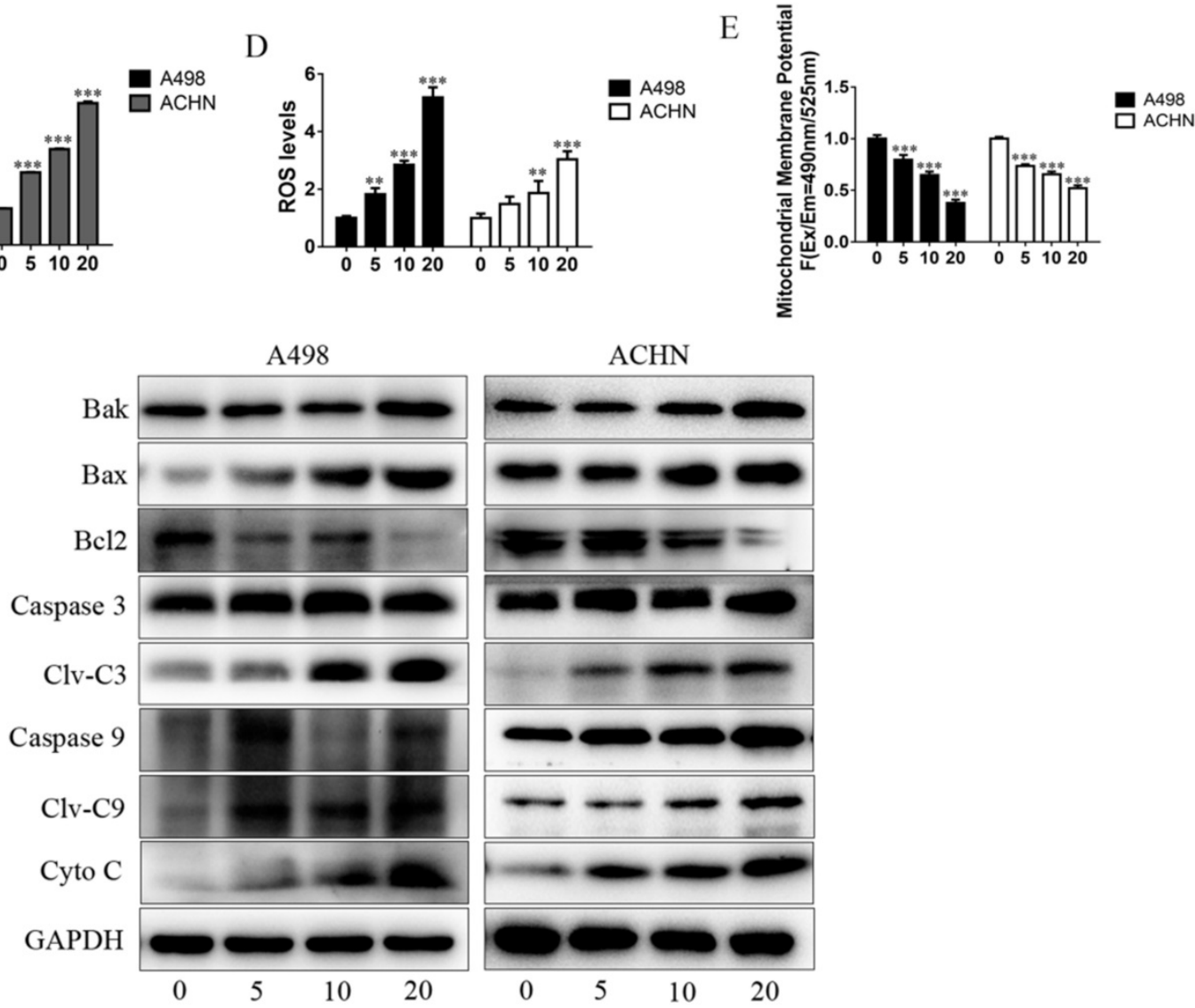

Figure 2. MET promoted apoptosis of RCC cells by increasing ROS production and mitochondria-dependent apoptotic pathway. RCC cell lines ACHN and A498 were exposed to various concentrations of MET (5,10, and $20 \mathrm{mM})$ for $24 \mathrm{~h}$, and the apoptosis rates (A and B), caspase-3/7 activity (C), intracellular level of total ROS (D), and mitochondrial membrane potential (E) were detected. (F) Expression of apoptotic proteins, such as caspase-3, caspase-9, Bak, Bax, Cyto C, and Bcl-2, were detected by Western blot. The data are presented as the mean \pm SD for at least three independent experiments. $* * P<0.01$ and $* * * P<0.001$ compared with untreated cells. 
The activity of caspase- $3 / 7$ and the expression of apoptotic proteins were detected in the RCC cells following treatment with MET for $24 \mathrm{~h}$. The results showed that MET increases the activity of caspase-3/7 (Figure 2C). The pro-apoptotic proteins such as cleaved caspase-3, cleaved caspase-9, Bak, Bax, and Cyto- $C$ were up-regulated, whereas the anti-apoptotic protein (Bcl-2) was down-regulated in a concentration-dependent manner in MET-treated cells compared with the controls (Figure 2F).

\section{MET + JS-K suppressed the RCC cell growth}

The RCC cells were exposed to MET $(1,5,10$, and $20 \mathrm{mM})$, JS-K $(0.5,1,2,5$, and $10 \mu \mathrm{M})$, or both for $48 \mathrm{~h}$. The MTT assay showed that cell viability was significantly inhibited by MET and JS-K and was significantly decreased when cells were treated using MET + JS-K in a concentration-dependent manner (Figure 3A). When the RCC and HK-2 cells were treated with MET (5 mM) and JS-K $(1 \mu \mathrm{M})$ for 12,24 , 48, and $72 \mathrm{~h}$, MET + JS-K suppressed RCC cell viability in a time-dependent manner but did not affect HK-2 cells (Figure 3B). Specifically, the RCC cells treated with MET (5 mM) and JSK $(1 \mu \mathrm{M})$, decreased cell number and changed cell morphology (Figure 3C). Moreover, MET + JS-K enhanced the effect. Figure 3D and E demonstrate that MET or JS-K alone suppressed cell colony formation, but MET + JS-K significantly suppressed RCC cell colony formations compared with the single drug.

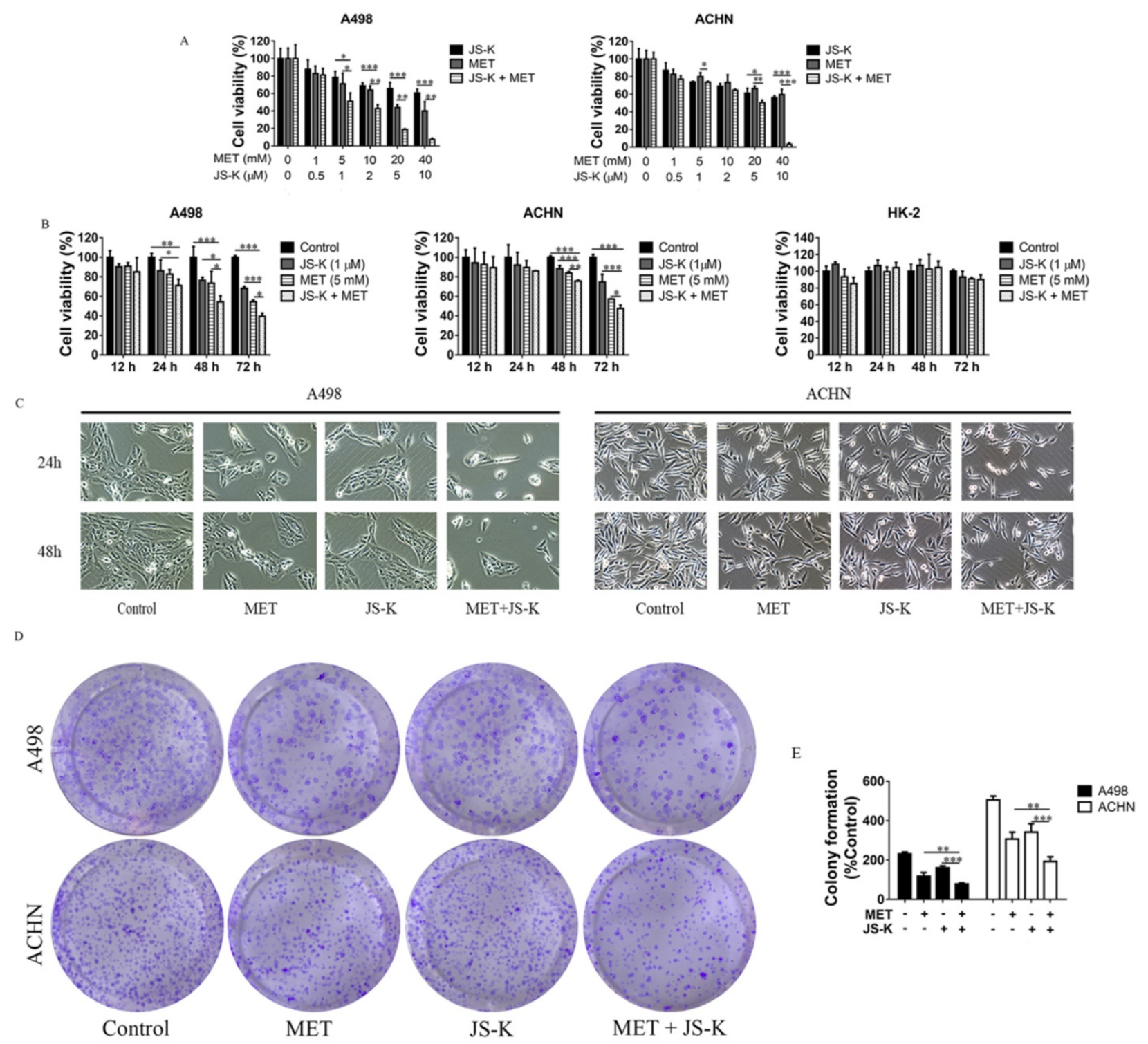

Figure 3. MET + JS-K suppressed RCC cell growth. (A) RCC cells were exposed to MET, JS-K, or both for 48 h. The MTT assay showed that cell growth was remarkably inhibited by MET and JS-K in a concentration-dependent manner. (B) MET + JS-K suppressed RCC cell proliferation in a time-dependent manner, but the human normal renal HK-2 cells were insensitive to either MET or JS-K. (C) Changes in the morphology of the ACHN and A498 cells treated with MET (5 mM) and JS-K ( $1 \mu M$ ). (D and E) MET and JS-K suppressed cell colony formation. The data are presented as the mean \pm SD for at least three experiments. $* P<0.05, * * P<0.01$, and $* * * P<0.001$ compared with untreated cells. 


\section{MET + JS-K promotes apoptosis in the RCC cells by increasing ROS production and activating mitochondria-dependent apoptotic pathway}

The RCC cells were exposed to MET ( $5 \mathrm{mM})$, JS-K $(1 \mu \mathrm{M})$, or MET+JS-K for $24 \mathrm{~h}$, and their apoptotic effect was investigated. The result showed that cell apoptosis is significantly promoted by MET + JS-K compared with MET or JS-K alone (Figure 4A and B). The effects of MET and JS-K on ROS production were evaluated. The ROS production in RCC cells treated with MET + JS-K was significantly increased (Figure
4D). Besides, the mitochondrial membrane potential was significantly decreased in the RCC cells treated with MET + JS-K compared with MET or JS-K treatments alone (Figure 4E).

The cells treated with MET + JS-K had a higher activity of caspase-3/7 (Figure 4C) than cells treated with MET or JS-K alone. The protein levels of Bax, Bak, Cyto-C, cleaved caspase-3, and cleaved caspase-9 were up-regulated in response to MET + JS-K, whereas the Bcl-2 levels were down-regulated (Figure $4 \mathrm{~F})$.
A
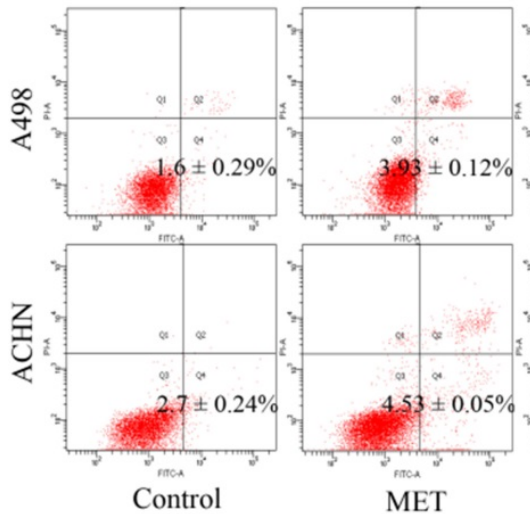

$\mathrm{C}$

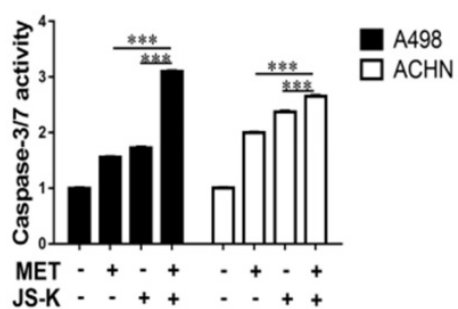

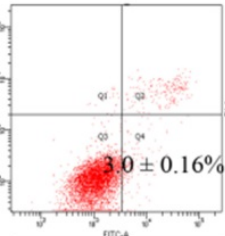

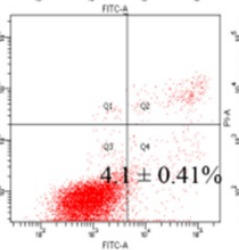

JSK
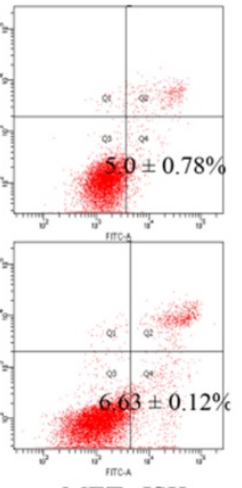

MET+JSK
D

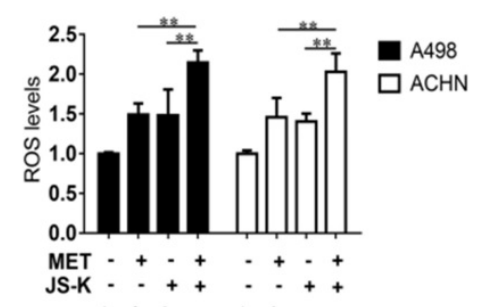

B

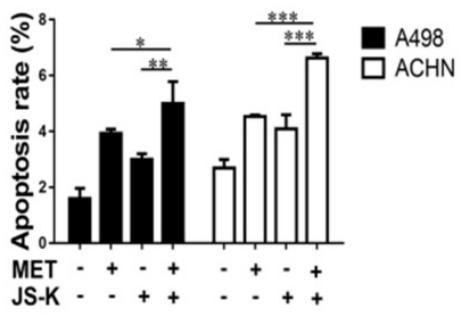

E

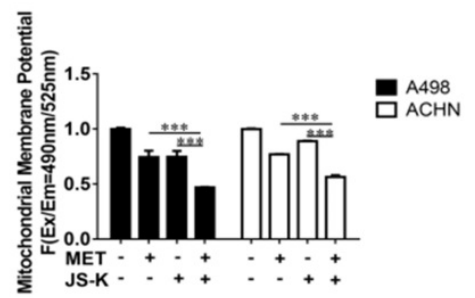

F

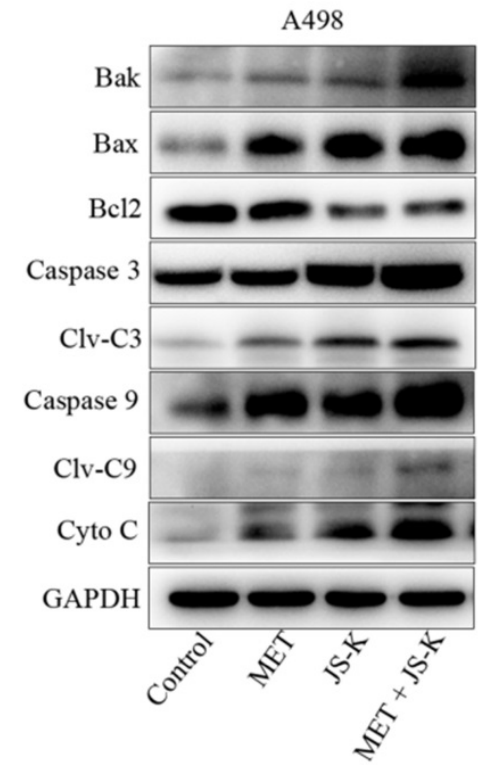

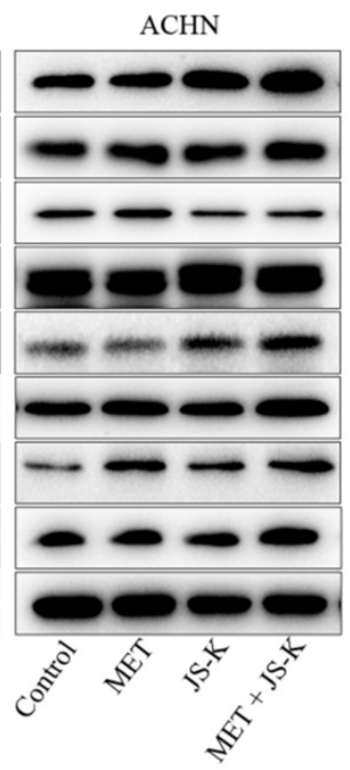

Figure 4. MET + JS-K promotes apoptosis in RCC cells by increasing ROS production and mitochondria-dependent apoptotic pathway. RCC cells were exposed to MET ( 5 mM), JS-K $(1 \mu \mathrm{M})$, or their combination for $24 \mathrm{~h}$. (A and B) Cell apoptosis rates. (C) Activity of caspase-3/7. (D) ROS production. (E) Mitochondrial membrane potential was tested. (F) Protein levels of Bax, Bak, Cyto C, cleaved caspase-3, and cleaved caspase-9 were detected by Western blot. The data are presented as the mean \pm SD for at least three independent experiments. $* P<0.05, * * P<0.01$, and $* * * P<0.001$ compared with untreated cells. 
A
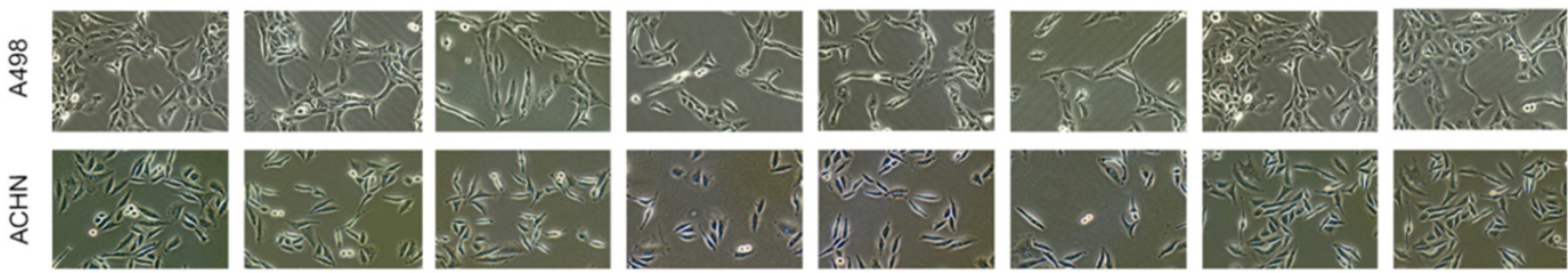

JS-K(1 $\mu \mathrm{M})$

$\operatorname{MET}(5 \mathrm{mU})$ $\operatorname{NAC}(100 \mu \mathrm{M})$ GSSG $(5 \mu \mathrm{M})$

B

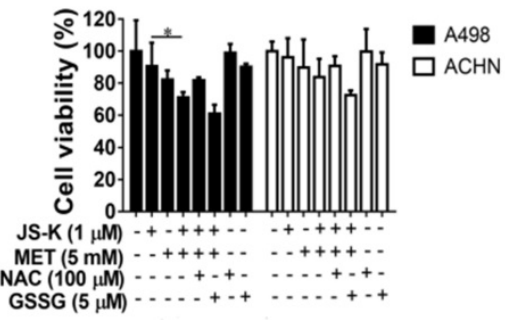

C

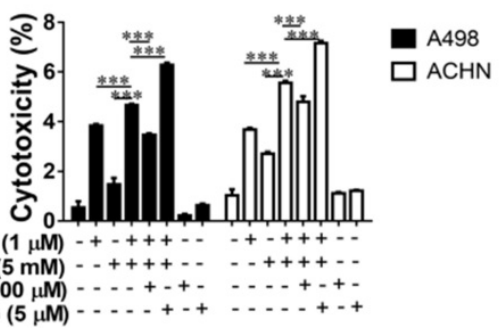

Figure 5. Anticancer activity of MET + JS-K on RCC cells was reversed by NAC and exacerbated by GSSG. The ACHN and A498 cells were cultured with $100 \mu M$ NAC or 5 $\mu M$ GSSG for $24 \mathrm{~h}$ and then treated with or without MET $(5 \mathrm{mM})+J S-K(1 \mu \mathrm{M})$. (A) Cells were visualized by microscopy (100x). (B) Cell survival was detected by MTT assay. (C) Cytotoxicity was investigated using an LDH Cytotoxicity Assay Kit. The data are presented as the mean \pm SD for three experiments. $* P<0.05$, $* * P<0.01$, and $* * * P<0.001$ compared with untreated cells.

A

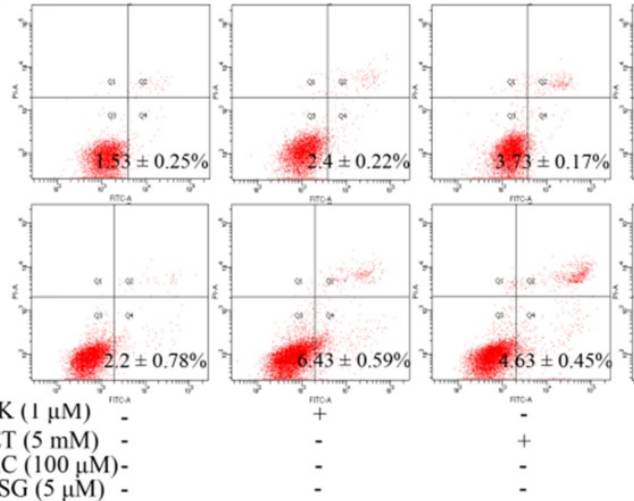

NAC $(100 \mu \mathrm{M})$.

$\operatorname{GSSG}(5 \mu \mathrm{M})$.

B

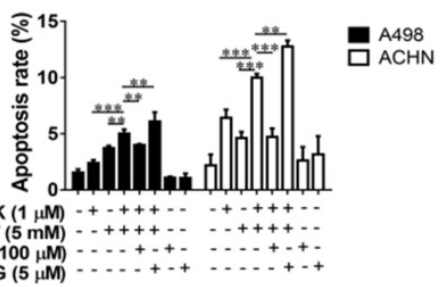

$\mathrm{C}$

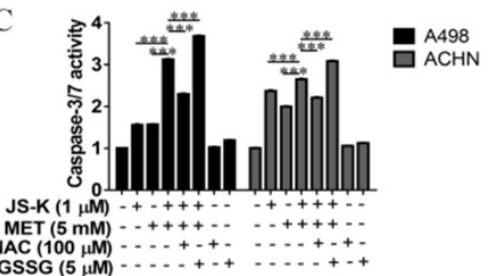

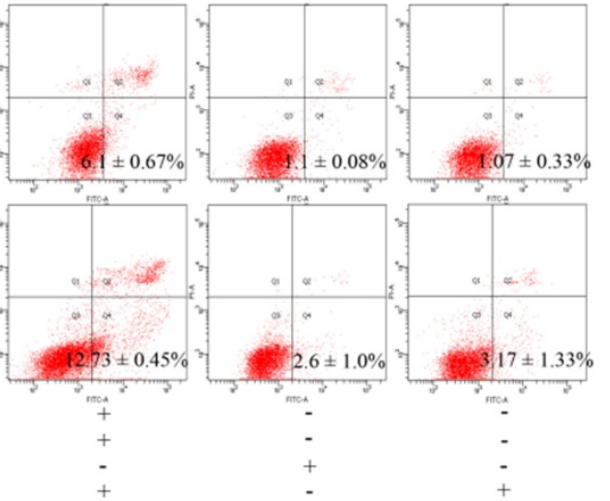

$\mathrm{D}$

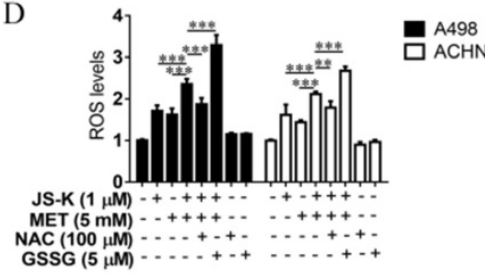

Figure 6. Effects of NAC and GSSG on MET and JS-K-induced cell apoptosis. The ACHN and A498 cells were cultured with $100 \mu M$ NAC or $5 \mu$ M GSSG for $24 \mathrm{~h}$ and then treated with or without MET $(5 \mathrm{mM})+\mathrm{JS}-\mathrm{K}(1 \mathrm{\mu M})$. (A and B) Apoptosis of cells was analyzed by FITC-annexin V/PI staining. Cumulative results were presented. (C) Caspase-3/7 activity of the ACHN and A498 cells. (D) Accumulation of intracellular ROS in RCC cells. The data are presented as the mean \pm SD for three independent experiments. $* * P<0.01$ and $* * * P<0.001$ compared with untreated cells.

Anticancer activity of MET + JS-K on the RCC cells was reversed by NAC and exacerbated by GSSG

The effects of ROS on MET and JS-K in the RCC cell proliferation suppression and apoptosis were explored using RCC cells ACHN and A498 treating with MET $(5 \mathrm{mM})$ and JS-K $(1 \mu \mathrm{M})$ in the presence or absence of the antioxidant $\mathrm{N}$-acetylcysteine (NAC; 100 $\mu \mathrm{M})$ or pro-oxidant oxidized glutathione (GSSG; 5 $\mu \mathrm{M})$ for $24 \mathrm{~h}$. NAC blocked MET+JS-K-induced cell growth suppression (Figure 5A and B), cell cytotoxicity (Figure 5C), apoptosis (Figure 6A and B), caspase-3/7 activity (Figure 6C), and ROS levels (Figure 6D). In contrast, treatment with GSSG augmented the MET+JS-K-induced cell growth 
inhibition (Figure 5A and B), cytotoxicity (Figure 5C), apoptosis (Figure 6A and B), caspase-3/7 activity (Figure 6C), and ROS levels (Figure 6D). These findings suggest that MET + JS-K inhibits cells growth and promotes the apoptosis of the RCC cells through ROS production.

\section{MET and JS-K increase DNA breaks and inhibit the expression of PCNA and Rad5 1}

The immunofluorescence analysis was used to detect $\gamma \mathrm{H} 2 \mathrm{AX}$ foci in the RCC cells. The concentrations of 5, 10, and $20 \mathrm{mM}$ MET alone or MET $(5 \mathrm{mM})+$ JS-K $(1 \mu \mathrm{M})$ were used to treat RCC cells for $48 \mathrm{~h}$. Figure 7A depicts the MET-induced DNA breaks in a concentration-dependent manner in the RCC cells ACHN and A498. In addition, MET + JS-K dramatically increased the DNA breaks compared with MET or JS-K alone (Figure 7C). We also detected the effect of MET alone or MET + JS-K on the expression of PCNA, Rad51, and $\gamma \mathrm{H} 2 \mathrm{AX}$-the three important proteins involved in the DNA break and repair. Figure 7B displays that MET extensively increased the expression of $\gamma \mathrm{H} 2 \mathrm{AX}$ and reduced the expression of PCNA and Rad51. Similar effects were seen after treatment with MET + JS-K compared with MET alone (Figure 7D). These data showed that MET increases DNA breaks in the RCC cells through modulation of the cellular DNA repair pathway, and the DNA damaging effects of MET are augmented when combined with JS-K.

\section{Discussion}

At present, surgery, chemotherapy, radiotherapy, immunotherapy, and molecular targeted therapy are the standard treatments for patients with RCC. However, the therapeutic effect of immunotherapy and molecular targeted therapy are limited given their high toxicity profile and cost [26, 27]. Moreover, advanced RCC is highly chemo-resistant $[5,6]$. Our goal is to identify an effective and less toxic treatment with few side effects for patients with RCC. MET is an appropriate drug with considerable anti-tumor effects and fewer side-effects. In the present study, MET inhibits proliferation and promotes apoptosis in the RCC cells ACHN and A498 in a concentration- and time-dependent manner, whereas these identical concentrations do not elicit cytotoxicity in normal renal tubular epithelial cells.

Apoptosis is a kind of programmed cell death produced by many physiological and pathological conditions and deregulated apoptotic signaling is considered to play a crucial role in the development and progression of cancer [28, 29]. Two ways by which cells can initiate apoptosis are mitochondrial and death receptor pathways [30]. Many chemical and physiological stimuli that can induce apoptosis are known to provoke oxidative stress by generating excess ROS, which suggests that abnormal ROS generation is closely associated with apoptosis [31]. Abnormal ROS generation plays a vital role in mitochondria-dependent apoptosis, known as intrinsic apoptosis. As signaling molecules, ROS participates in multiple cellular functions, including cell proliferation, cell cycle progression, invasion, migration, and apoptosis in cancer [32]. ROS generations induce damage and depolarization of the mitochondrial membrane and accordingly decrease mitochondrial membrane potential and increase the levels of other pro-apoptotic molecules in the cells [33]. Considerable research has indicated that a high level of ROS is required for initiating apoptotic responses, which is often one of the prominent mechanisms of several anticancer drugs. Therefore, we examined the induction of ROS, alterations in mitochondrial membrane potential, and the onset of apoptosis at various concentrations of MET on the RCC cells ACHN and A498. Our findings provide direct evidence that MET enhances ROS generation, induces damage, and depolarizes the mitochondrial membrane in the RCC cells. These factors are responsible for the pro-apoptotic effects of MET on the RCC cells. Figure 2 displays that MET induces apoptosis and ROS generation; decreases mitochondrial membrane potential; up-regulates protein levels of Bax, Bak, Cyto-C, cleaved caspase-3, and cleaved caspase-9; and down-regulates Bcl-2 in the ACHN and A498 cells, thus indicating that MET exerts anticancer activity by increasing ROS production and inducing mitochondria-dependent apoptosis. In addition, as ROS have a short-half life, highly reactivity, and an electronegative oxygen, they can induce DNA damage and affect the DNA damage response [34]. Chemotherapeutic agents, such as doxorubicin and cisplatin, increase ROS levels, which contribute to their cytotoxicity by increasing DNA damage $[35,36]$. To evaluate whether MET induces DNA damage in ACHN and A498, the immunofluorescence analyses was used to detect $\gamma \mathrm{H} 2 \mathrm{AX}$ foci, an important marker for DNA damage in the cells. Our results showed that the number of $\gamma \mathrm{H} 2 \mathrm{AX}$ foci increased in cells treated with 5, 10, and $20 \mathrm{mM}$ MET, thereby indicating that MET induces DNA damage in RCC cells ACHN and A498 in a concentrationdependent manner (Figure 7A). Analogously, the expression of the $\mathrm{\gamma}-\mathrm{H} 2 \mathrm{AX}$ protein in the RCC cells treating with MET was increased (Figure 7B). The increased cellular DNA damage might be caused by the excess ROS generation and result in subsequent apoptosis and suppression of proliferation in the RCC cells ACHN and A498. Furthermore, MET suppressed 
the growth of carcinoma cells by inhibiting the DNA damage repair pathway [37]. To assess the role of MET in regulating cellular DNA repair, we assessed the effect of MET on the expression of PCNA and Rad51, the two markers that serve crucial functions in
DNA repair. The data revealed that MET extensively restrains the expression level of PCNA and Rad51 (Figure 7B), thus suggesting that MET increases genotoxicity in RCC cells by decreasing the cellular DNA repair mechanisms.
A

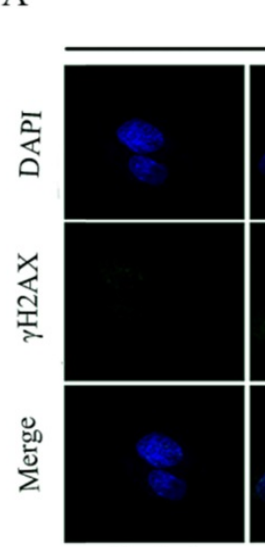

Control

B

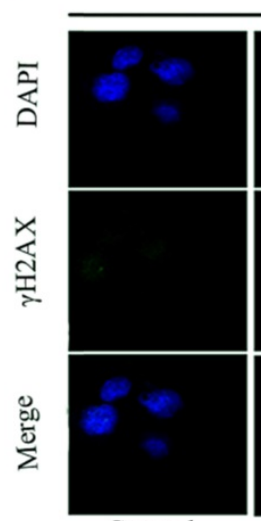

Control
A498

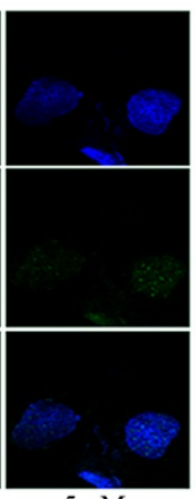

$5 \mathrm{mM}$

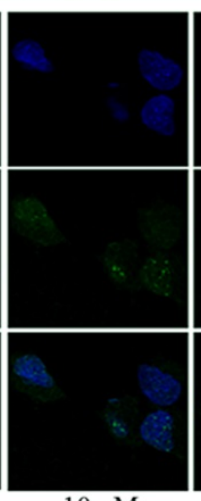

$10 \mathrm{mM}$

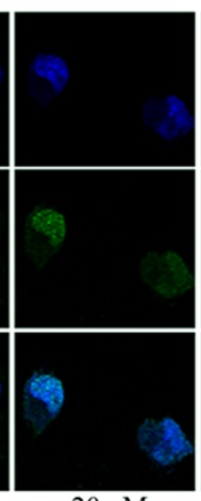

$20 \mathrm{mM}$

A498

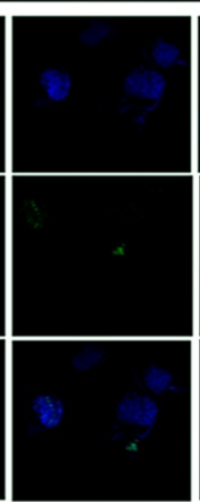

MET

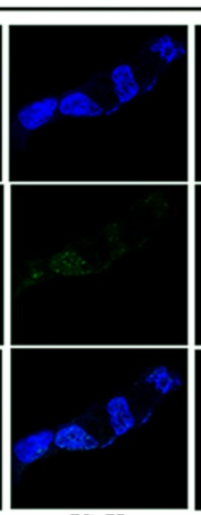

JS-K

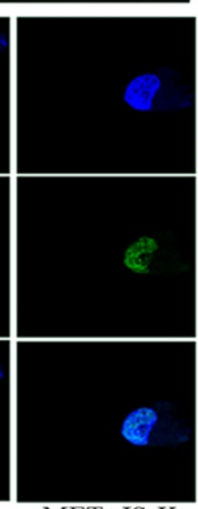

MET+JS-K

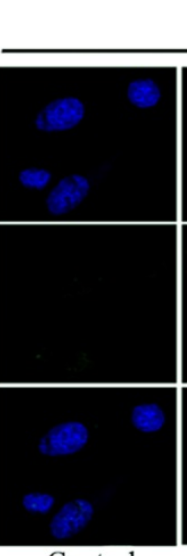

Control
ACHN

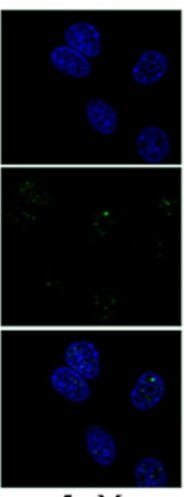

$5 \mathrm{mM}$

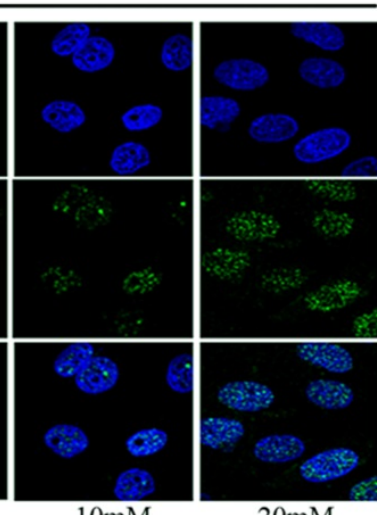

$10 \mathrm{mM}$

$20 \mathrm{mM}$

$\mathrm{ACHN}$

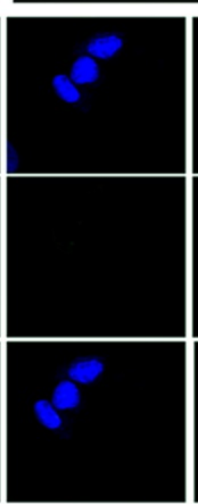

Control

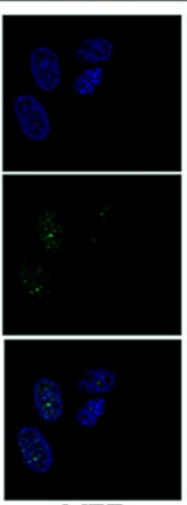

MET

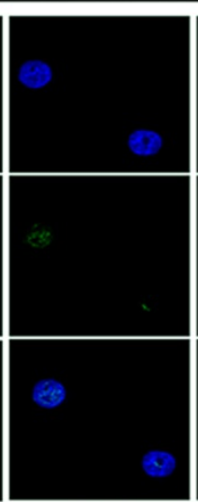

JS-K

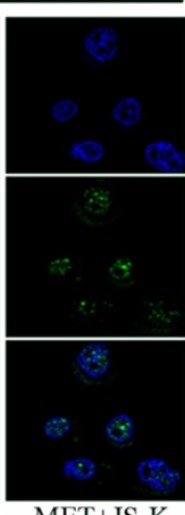

MET+JS-K

C

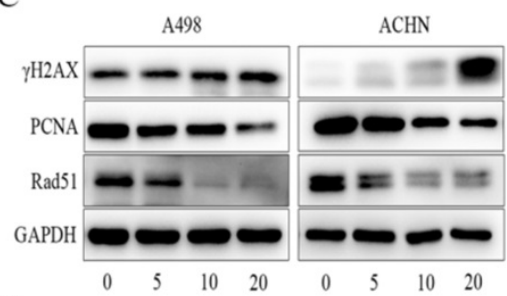

D
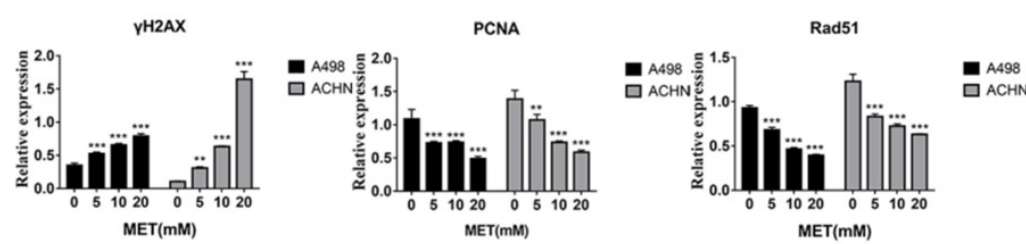

F

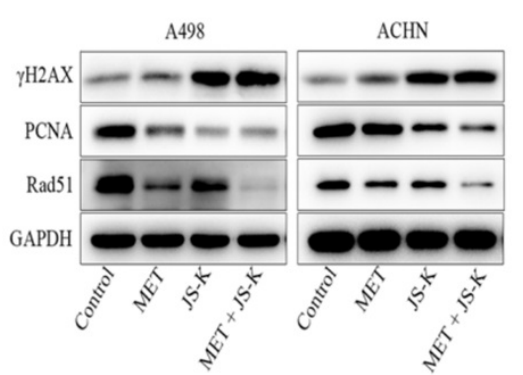

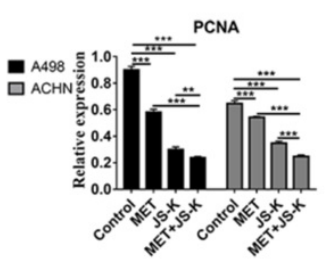

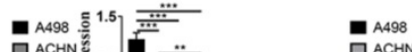

Figure 7. MET and JS-K increased DNA breaks and restrained the expression of PCNA and Rad51. The $\mathrm{YH} 2 \mathrm{AX}$ foci in the RCC cells were tested by immunofluorescence analysis. (A) MET increased $\mathrm{YH} 2 \mathrm{AX}$ foci to induce DNA breaks in a concentration-dependent manner in the RCC cells ACHN and A498. (C) MET + JS-K dramatically increased DNA breaks compared with MET or JS-K alone. (B and E) Effect of MET alone or MET + JS-K (1 $\mu$ M) on the expression of PCNA, and Rad51 and YH2AX were detected through Western blot assay. (D, F) All three proteins were quantified using Image J software and normalized against GAPDH. 
In addition, our previous study demonstrated that adding JS-K up-regulates p53 and increases intracellular ROS accumulation to upsurge the anticancer effects of doxorubicin [38]. In the study, inhibiting RCC cell growth was further potentiated when JS-K was added. This combined effect may be related to intracellular ROS accumulation because excess ROS generation is considered to sensitize tumor cells to chemotherapy drugs $[39,40]$. Therefore, we hypothesized that JS-K would increase the generation of ROS in RCC cells, which would subsequently sensitize them to even a low level of MET. Our study showed that MET + JS-K remarkably increases the generation of ROS, suppresses proliferation (Figure 3), and induces mitochondriadependent apoptosis (Figure 4) and DNA breaks (Figure 7C and D) compared to treatment with MET or JS-K alone. Moreover, the enhanced cytotoxic effect by combining the agents was largely abolished by NAC and exacerbated by GSSG (Figure 5 and 6). Thus, MET + JS-K reactivated oxygen species activation, induced DNA breaks, and increased the inhibition of RCC cell growth.

In conclusion, our studies revealed that MET inhibits cell proliferation and induces apoptosis and DNA breaks in the RCC cells ACHN and A498. Moreover, treatment with MET + JS-K synergistically inhibits cell growth and induces cell apoptosis and DNA breaks in the RCC cells through ROS activation. This combination therapy could be a promising option for patients with RCC.

\section{Abbreviations}

MET: Metformin; RCC: human renal cell carcinoma; $\Delta \psi \mathrm{m}$ : mitochondrial transmembrane potential; PBS: phosphate buffer saline; DMSO: dimethyl sulfoxide; NAC: N-acetylcysteine; GSSG: glutathione disulfide; HRP: Horseradish peroxidase; MTT: methyl-tetrazolium; LDH: lactate dihydrogenase; FITC: fluorescein isothiocyanate; RIPA: radio immunoprecipitation Assay; SDS-PAGE: sodium dodecyl sulfate polyacrylamide gel electrophoresis; TBST: Tris-buffered saline and 1\% Tween 20.

\section{Acknowledgements}

This work was supported by the grants: Scientific Research Fund of Guangdong Medical University (No. M2017038); The National Natural Science Funds (No. 81272833) of China.

\section{Author contributions}

$Y Z$ and JL designed the experiments. $Y Z, Q L$, JM, JL, DY, ZA, and LC performed the experiments. YZ performed statistical analyses. YZ and QL wrote the article, JM contributed to revision of the article. $Y Z$ prepared figures. JL and YZ provided the supervision and the financial support. All authors reviewed and approved the manuscript.

\section{Competing Interests}

The authors have declared that no competing interest exists.

\section{References}

1. Decastro GJ, McKiernan JM. Epidemiology, clinical staging, and presentation of renal cell carcinoma. Urol Clin North Am. 2008; 35: 581-92.

2. Jabaji RB, Fischer $H$, Kern $T$, et al. Trend of Surgical Treatment of Localized Renal Cell Carcinoma. Perm J. 2019; 23: 18-108.

3. Siegel RL, Miller KD, Jemal A. Cancer statistics. CA Cancer J Clin. 2015; 65: 5-29.

4. Ljungberg B, Bensalah $\mathrm{K}$, Canfield $\mathrm{S}$, et al. EAU guidelines on renal cell carcinoma: 2014 update. Eur Urol. 2015; 67: 913-24.

5. Longo R, D'Andrea MR, Sarmiento R, et al. Integrated therapy of kidney cancer. Ann Oncol. 2007; 18 (Suppl 6): vi141-8.

6. Juloori A, Miller JA, Parsai S, et al. Overall survival and response to radiation and targeted therapies among patients with renal cell carcinoma brain metastases. J Neurosurg. 2019; 18: 1-9.

7. Heckman-Stoddard BM, DeCensi A, Sahasrabuddhe VV, et al. Repurposing metformin for the prevention of cancer and cancer recurrence. Diabetologia. 2017; 60: 1639-47.

8. Hundal HS, Ramlal T, Reyes R, et al. Cellular mechanism of metformin action involves glucose transporter translocation from an intracellular pool to the plasma membrane in L6 muscle cells. Endocrinology. 1992; 131: 1165-73.

9. Li X, Zhang N, Li Y, et al. Effects of metformin and rosiglitazone on peripheral insulin resistance and beta-cell function in obesity: a double-blind, randomized, controlled study. J Int Med Res. 2011; 39: 358-65.

10. Witters LA. The blooming of the French lilac. J Clin Invest. 2001; 108: 1105-7.

11. Evans JM, Donnelly LA, Emslie-Smith AM, et al. Metformin and reduced risk of cancer in diabetic patients. BMJ. 2005; 330: 1304-5.

12. Ben Sahra I, Le Marchand-Brustel Y, Tanti JF, et al. Metformin in cancer therapy: a new perspective for an old antidiabetic drug? Mol Cancer Ther. 2010; 9: 1092-9.

13. Deng J, Peng $M$, Wang $Z$, et al. Novel application of metformin combined with targeted drugs on anticancer treatment. Cancer Sci. 2019; 110: 23-30.

14. Higurashi T, Nakajima A. Metformin and Colorectal Cancer. Front Endocrinol. 2018; 9: 622.

15. Broadhurst PJ, Hart AR. Metformin as an Adjunctive Therapy for Pancreatic Cancer: A Review of the Literature on Its Potential Therapeutic Use. Dig Dis Sci. 2018; 63: 2840-52

16. Mormile R. Metformin Therapy and Breast Cancer Incidence and Mortality-Letter. Cancer Epidemiol Biomarkers Prev. 2018; 27: 1384

17. Jaune E, Rocchi S. Metformin: Focus on Melanoma. Front Endocrinol. 2018; 9: 472

18. Shami PJ, Saavedra JE, Wang LY, et al. JS-K, a glutathione/glutathione S-transferase-activated nitric oxide donor of the diazeniumdiolate class with potent antineoplastic activity. Mol Cancer Ther. 2003; 2: 409-17.

19. Laschak M, Spindler KD, Schrader AJ, et al. JS-K, a glutathione/glutathione S-transferase-activated nitric oxide releasing prodrug inhibits androgen receptor and WNT-signaling in prostate cancer cells. BMC Cancer. 2012; 12: 130.

20. Gunzle J, Osterberg N, Saavedra JE, et al. Nitric oxide released from JS-K induces cell death by mitotic catastrophe as part of necrosis in glioblastoma multiforme. Cell Death Dis. 2016; 7: e2349.

21. Qiu M, Chen $\mathrm{L}$, Tan $\mathrm{G}$, et al. A reactive oxygen species activation mechanism contributes to JS-K-induced apoptosis in human bladder cancer cells. Sci Rep. 2015; 5: 15104

22. McMurtry V, Saavedra JE, Nieves-Alicea R, et al. JS-K, a nitric oxide-releasing prodrug, induces breast cancer cell death while sparing normal mammary epithelial cells. Int J Oncol. 2011; 38: 963-71.

23. Siddiqui MS, Francois M, Fenech MF, et al. Persistent gammaH2AX: A promising molecular marker of DNA damage and aging. Mutat Res Rev Mutat Res 2015; 766: 1-19.

24. Boehm EM, Gildenberg MS, Washington MT. The Many Roles of PCNA in Eukaryotic DNA Replication. Enzymes. 2016; 39: 231-54.

25. Bhattacharya $S$, Srinivasan $K$, Abdisalaam $S$, et al. RAD51 interconnects between DNA replication, DNA repair and immunity. Nucleic Acids Res. 2017; 45: 4590-605.

26. Motzer RJ, Basch E. Targeted drugs for metastatic renal cell carcinoma. Lancet. 2007; 370: 2071-3.

27. Nagyivanyi K, Geczi L. [Targeted treatment of renal cell carcinoma, treatment caused side-effects and side-effect management]. Orv Hetil. 2017; 158: $1488-502$

28. Queiroz EA, Fortes ZB, da Cunha MA, et al. Antiproliferative and pro-apoptotic effects of three fungal exocellular beta-glucans in MCF-7 breast cancer cells is mediated by oxidative stress, AMP-activated protein kinase 
(AMPK) and the Forkhead transcription factor, FOXO3a. Int J Biochem Cell Biol. 2015; 67: 14-24.

29. Zhang $X$, Wang $X, W u ~ T$, et al. Isoliensinine induces apoptosis in triple-negative human breast cancer cells through ROS generation and p38 MAPK/JNK activation. Sci Rep. 2015; 5: 12579.

30. Ouyang L, Shi Z, Zhao S, et al. Programmed cell death pathways in cancer: a review of apoptosis, autophagy and programmed necrosis. Cell Prolif. 2012; 45: 487-98.

31. Pathak N, Khandelwal S. Oxidative stress and apoptotic changes in murine splenocytes exposed to cadmium. Toxicology. 2006; 220: 26-36.

32. Zou $\mathrm{Z}$, Chang $\mathrm{H}, \mathrm{Li} \mathrm{H}$, et al. Induction of reactive oxygen species: an emerging approach for cancer therapy. Apoptosis. 2017; 22: 1321-35.

33. Wu CC, Bratton SB. Regulation of the intrinsic apoptosis pathway by reactive oxygen species. Antioxid Redox Signal. 2013; 19: 546-58.

34. Srinivas US, Tan BWQ, Vellayappan BA, et al. ROS and the DNA damage response in cancer. Redox Biol. 2018; 25: 101084.

35. Conklin KA. Chemotherapy-associated oxidative stress: impact on chemotherapeutic effectiveness. Integr Cancer Ther. 2004; 3: 294-300.

36. Marullo R, Werner E, Degtyareva N, et al. Cisplatin induces a mitochondrial-ROS response that contributes to cytotoxicity depending on mitochondrial redox status and bioenergetic functions. PLoS One. 2013; 8: e81162.

37. Li H, Chen $\mathrm{X}, \mathrm{Yu} \mathrm{Y}$, et al. Metformin inhibits the growth of nasopharyngeal carcinoma cells and sensitizes the cells to radiation via inhibition of the DNA damage repair pathway. Oncol Rep. 2014; 32: 2596-604.

38. Qiu M, Ke L, Zhang S, et al. JS-K, a GST-activated nitric oxide donor prodrug, enhances chemo-sensitivity in renal carcinoma cells and prevents cardiac myocytes toxicity induced by Doxorubicin. Cancer Chemother Pharmacol. 2017; 80: 275-86

39. Cui $Q$, Wang JQ, Assaraf YG, et al. Modulating ROS to overcome multidrug resistance in cancer. Drug Resist Updat. 2018; 41: 1-25.

40. Trachootham D, Alexandre J, Huang P. Targeting cancer cells by ROS-mediated mechanisms: a radical therapeutic approach?. Nat Rev Drug Discov. 2009; 8: 579-91 